\title{
Criação de Narrativas Digitais Utilizando Elementos das Redes Sociais para Apoiar o Ensino de Eletrônica
}

Iury Rodrigues Ferreira - Instituto Federal de Educação, Ciência e Tecnologia de São Paulo (IFSP) - iury.ferreira@aluno.ifsp.edu.br

Nemésio Freitas Duarte Filho - Instituto Federal de Educação, Ciência e Tecnologia de São Paulo (IFSP) - nemesio@ifsp.edu.br

\begin{abstract}
Resumo. As narrativas digitais vêm sendo utilizadas em diversas áreas do conhecimento, proporcionando ludicidade ao processo de ensino, inclusive por meio do apoio das redes sociais. O ensino na área de Eletrônica pode ser apoiado pela utilização de narrativas digitais. Neste contexto, este trabalho discute a criação de narrativas digitais utilizando elementos das redes sociais para auxiliar o ensino na disciplina de Eletrônica Básica. O conteúdo educacional das narrativas foi modelado por meio da criação de personagens e diálogos, sendo avaliado por docentes e alunos. Os resultados demonstram que as narrativas apresentam uma organização didática bem estruturada, proporcionando maior engajamento e motivação por parte dos usuários.
\end{abstract}

Palavras-Chave: Narrativas Digitais. Redes Sociais. Ensino de Eletrônica.

\section{Creation of Digital Narratives Using Elements of Social Networks to Support for Electronic Teaching}

\begin{abstract}
Digital narratives have been used in several areas of knowledge, providing engagement to the teaching process, assisted by the support of social networks. Teaching in the field of Electronics can be supported by the use of digital narratives. In this context, this work discusses the creation of digital narratives using elements of social networks to assist teaching in the discipline of Basic Electronics. The educational content of the narratives was modeled through the creation of characters and dialogues, being evaluated by teachers and students. The results demonstrate that the narratives present a structured didactic organization, providing greater engagement and motivation on the part of the users.
\end{abstract}

Keywords: Digital Narratives. Social networks. Electronics Teaching.

\section{Introdução}

Diferentes pesquisas vêm apontando vantagens do uso de Tecnologias da Informação e Comunicação (TIC) na educação. As redes sociais são um exemplo, pois sendo parte do cotidiano social geram identificação imediata por parte dos alunos, contribuindo para engajá-los ao longo do processo de ensino (Araújo, 2010). Atrelado a esse cenário, as narrativas digitais também estão se destacando. Segundo Almeida e Valente (2012), elas aparecem com uma possibilidade de utilizar novas tecnologias para contar histórias. Trata-se de um enriquecimento da narrativa, comumente caracterizada pela oralidade e a escrita.

Dentre as vantagens de uso das narrativas digitais no ensino, está o fato de possibilitarem um cenário mais lúdico aos alunos, pois permitem articular sons/imagens 
para transmitir conhecimentos (Junior et al., 2012), podendo ser desenvolvidas a partir da criação de personagens e diálogos, tendo como suporte, inclusive, as redes sociais.

A integração entre narrativas digitais e redes sociais pode ser utilizada e desenvolvida para apoiar o aluno no aprendizado de temas nas mais variadas áreas de conhecimento, entre elas, a Engenharia. Este apoio educacional por meio de narrativas digitais pode e já tem proporcionado maior motivação e interatividade para os alunos, além de possibilitar maior flexibilidade no ensino (Fischer e Duarte Filho, 2018).

Dentro da perspectiva apresentada, este artigo discute a proposta de desenvolvimento de narrativas digitais por meio de elementos das redes sociais com foco no auxílio da disciplina de Eletrônica Básica. O conteúdo didático das narrativas está associado com os componentes elétricos/eletrônicos. As narrativas digitais descrevem personagens estereotipados e situações relacionadas ao contexto de vivência dos próprios alunos, constituindo um conteúdo lúdico e motivador.

Pretende-se, com isso, contribuir para a melhoria e qualificação acadêmica dos alunos na área de Engenharia e, mais especificamente, dentro do contexto dos componentes elétricos/eletrônicos. De fato, tais componentes possuem uma grande importância dentro da área de automação e indústria. A aprendizagem e ensino desses componentes requer temáticas práticas e teóricas, no entanto, ainda há dificuldades e desinteresse na parte teórica desse conteúdo, sobretudo em virtude da falta de materiais didáticos atrativos e diversificados. Assim, conhecer/entender por meios lúdicos os fundamentos que norteiam esta área é um aspecto importante para o entendimento em relação a utilização e identificação desses componentes no contexto industrial.

O artigo encontra-se organizado como se segue. A Seção 2 apresenta a base teórica sobre redes sociais aplicadas ao ensino-aprendizagem, e narrativas digitais no contexto educacional. A Seção 3 traz uma visão geral das narrativas digitais criadas por meio das redes sociais, descrevendo aspectos da sua criação e principais características. A Seção 4 apresenta a avaliação prática das narrativas digitais. Por fim, a Seção 5 apresenta as conclusões e perspectivas para trabalhos futuros.

\section{Referencial Teórico}

\subsection{Redes Sociais Aplicadas ao Ensino-Aprendizagem}

Para Werhmuller e Silveira (2012), a internet passou da utilização para formas de partilha e construção de conteúdos. Inclusive, nos dias de hoje, a evolução da tecnologia coloca a internet acessível por meio de dispositivos móveis, o que potencializa ainda mais a fluidez das relações no ciberespaço (Caritá et al., 2011).

Exemplo disso são as redes sociais, motivadas pela busca dos indivíduos em estabelecerem relações e trocas a partir de interesses comuns, ganharam novas dimensões com o ciberespaço (Souza e Schneider, 2012). Para Souza e Schneider (2012), as relações no espaço virtual fomentam interações mais espontâneas e horizontais, as quais estimulam as trocas e a colaboração entre os sujeitos.

Dentre as características das redes sociais, podemos apontar a criação de perfis pelos usuários e, a partir destes, o uso de páginas de recados, a participação em comunidades, o compartilhamento de diferentes mídias, que ocorrem por meio da relação virtual entre diferentes pessoas, as quais possuem diferentes culturas, condições sociais, formações e orientações políticas (Araújo, 2010).

Para Caritá et al. (2011), as redes sociais podem estimular a busca por conteúdos, funcionarem como repositórios de objetos de aprendizagem, além de promover um espaço para discussões que envolvem a troca de conhecimentos. Da mesma forma, V. $18 \mathrm{~N}^{\circ} 1$, julho, 2020 RENOTE DOI: 
Werhmuller e Silveira (2012) consideram que a dinâmica das redes sociais pode estimular a curiosidade e o interesse dos alunos, podendo servir como espaço para o reforço/revisão de conteúdos, além de melhorar as relações sociais entre alunos e professores.

Entretanto, mesmo diante dos benefícios, as redes sociais apresentam desafios, dentre os quais é possível destacar: (1) o preparo deficitário dos professores (Souza e Schneider, 2012); (2) a necessidade de educar os usuários para o uso consciente (Caritá et al., 2011); (3) a necessidade de superação da desconfiança das instituições de ensino; e (4) a ausência de recursos tecnológicos nas instituições, juntamente com a falta de processos pedagógicos e padrões de utilização (Araújo, 2010).

No que diz respeito às dificuldades de planejamento de atividades pedagógicas que incorporam as redes sociais, isso se dá pela falta de familiaridade dos docentes e pelo fato de serem inúmeros os recursos e possibilidades oferecidos, como, por exemplo, a criação de perfis, o uso de páginas de recado, a participação em comunidades, o compartilhamento de notícias, a utilização de animações, narrativas digitais, a publicação de diferentes mídias, entre outros aspectos.

Nesse contexto, dos recursos apresentados anteriormente, as narrativas digitais podem ser utilizadas em conjunto com as redes sociais. Isso porque, o contar histórias foi potencializado com a disponibilidade de diferentes mídias (Almeida e Valente, 2014).

\subsection{Narrativas Digitais no Contexto Educacional}

Segundo Almeida e Valente (2012), a possibilidade de utilização das TICs e das tecnologias digitais na produção de narrativas vem sendo pesquisada por diversos autores a partir de diferentes denominações, entre as quais se encontram: histórias digitais, narrativas interativas, narrativas multimídia, entre outros termos.

Para Prado et al. (2017, p. 1160), “[...] a concepção de narrativas digitais passa a ocorrer a partir de um processo de produção textual, que se apropria do caráter recente dos processos audiovisuais e tecnológicos aptos a inovar o ato de contar histórias [...]", mantendo elementos básicos da narrativa, como, por exemplo, o enredo, os personagens e o espaço-tempo. De forma resumida, narrativas digitais se constituem na junção entre o ato de contar uma história em um contexto de multimídia (Prado et al., 2017; Azeredo e Reategui, 2013).

Nessa mesma perspectiva, segundo Fischer e Duarte Filho (2018), as narrativas digitais configuram-se como um instrumento pedagógico capaz de gerar motivação, eficácia e, além disso, coloca o trabalho docente próximo a realidade vivida pelos educandos, já que os alunos são usuários dessas novas tecnologias digitais.

Ainda conforme Prado et al. (2017), entre os pontos positivos do uso das narrativas digitais, vários podem ser destacados, já que o uso das mesmas contribui com: (1) a aprendizagem, já que favorece a troca de conhecimentos; (2) a ludicidade, pois oferece diferentes formas de se tratar um assunto; (3) o letramento, já que o aluno aprende a lidar com diferentes formas de linguagem; e (4) a criatividade, já que os alunos podem articular os diferentes recursos tecnológicos de acordo com sua imaginação e intenção.

Exemplos de narrativas digitais podem ser encontrados na internet. Um dos exemplos é a "História da Segunda Guerra Mundial", criada a partir de um template editável da rede social Facebook (Figura 1). No exemplo apresentado, é possível notar a criação de perfis que representam os diferentes países que participaram do conflito, além de apresentar de maneira simples e lúdica os fatos que ocorreram por meio de diálogos.

V. $18 \mathrm{~N}^{\circ} 1$, julho, 2020 RENOTE DOI: 
As redes sociais podem ser consideradas uma boa ferramenta para a criação de narrativas digitais, pois permitem que num mesmo espaço seja possível articular diferentes recursos e funcionalidades. Mas é preciso considerar algumas problemáticas em relação à construção de narrativas digitais por meio de redes sociais, sobretudo por consistir em um contexto novo e haver ausência de diretrizes sobre boas práticas que possam orientar os professores no desenvolvimento de tais narrativas.

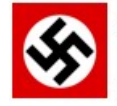

Que tal dividirmos a Polônia?

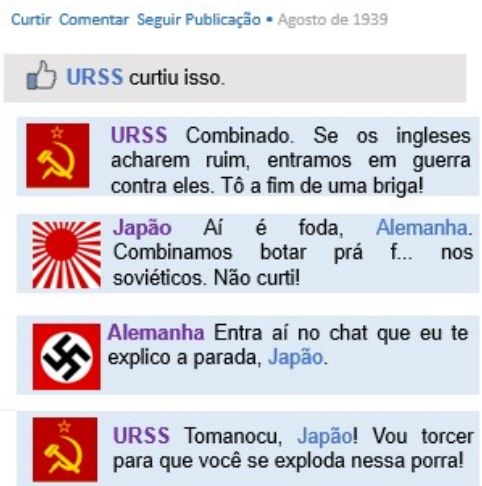

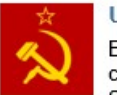

Encontrei isso aqui na Polônia. Chamam de campo de concentração de Auschwitze e tava cheio de judeus Soube que mataram 1 milhão só por aquil

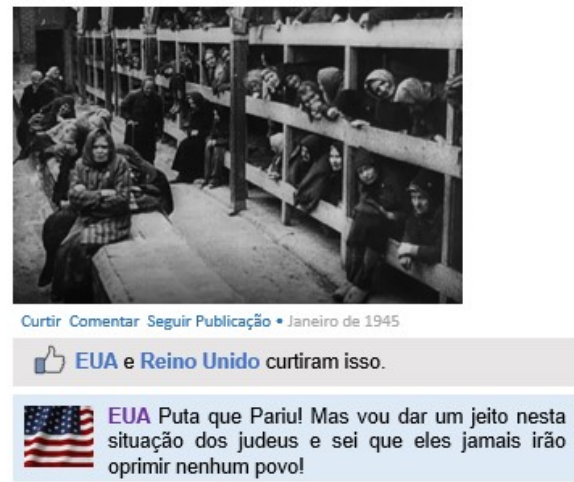

Figura 1 - Trecho da história da segunda guerra mundial contada por meio de uma narrativa digital ${ }^{1}$

\section{Criação e Apresentação das Narrativas Digitais}

As narrativas digitais propostas neste trabalho, utilizando elementos das redes sociais, possuem um objetivo de apoiar e motivar o ensino dos componentes elétricos/eletrônicos na disciplina de Eletrônica Básica, contribuindo na elaboração de um recuso didático lúdico e ajudando na disseminação do conhecimento em geral. Os usuários em sua maioria são alunos do ensino médio (em virtude dos aspectos lúdicos) podendo também ser utilizados por docentes da área.

\subsection{Processo de Elaboração das Narrativas Digitais}

Para o desenvolvimento das narrativas digitais, os autores se basearam em um processo sistemático de criação de narrativas digitais utilizando elementos de redes sociais (Fischer e Duarte Filho, 2018). Algumas atividades presentes no processo em questão foram modificadas e adaptadas ao presente trabalho, sendo descritas a seguir (Figura 2).

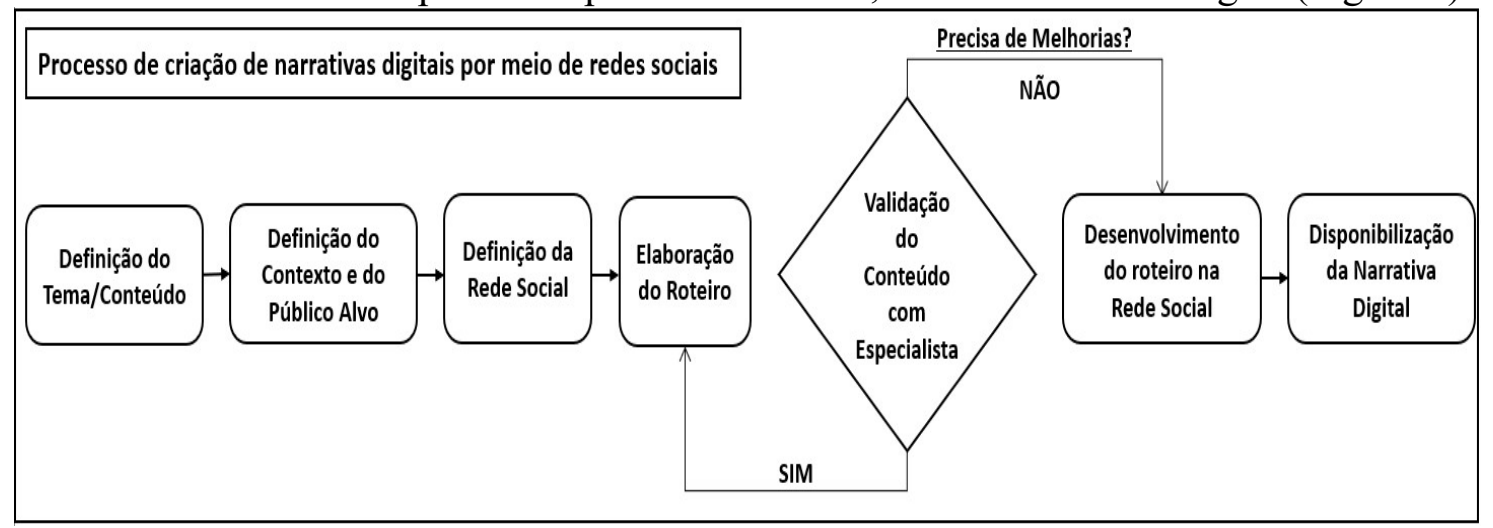

\footnotetext{
${ }^{1}$ https://www.oversodoinverso.com.br/explicando-a-segunda-guerra-mundial-atraves-dofacebook/

V. $18 \mathrm{~N}^{\mathrm{o}} 1$, julho, 2020 RENOTE DOI:
} 


\section{Figura 2 - Processo de Criação de Narrativas Digitais por Meio de Redes Sociais (Fischer e Duarte Filho, 2018).}

Definição do Tema/Conteúdo: nesta atividade é preciso ter clareza sobre o tema que será abordado e quais enfoques (subtemas/conteúdos específicos) serão trabalhados. Deve-se pesquisar informações relacionadas aos objetivos elencados, em diferentes linguagens (escrita, visual, audiovisual etc.), e identificados os personagens. No atual trabalho foi escolhido e pesquisado a temática "Componente Elétricos/Eletrônicos" com foco nos elementos: resistor, capacitor, indutor, diodo e transistor.

Definição do Contexto e do Público-alvo: para essa atividade é necessário refletir sobre qual a linguagem mais apropriada para a turma/curso em que será desenvolvido o recurso didático. Para o atual trabalho, o público-alvo são alunos do Ensino Médio e a utilização da narrativa digital será na própria sala de aula. Além disso, o contexto em que será utilizado o recurso didático é para o aprofundamento do ensino do conteúdo na disciplina de eletrônica básica.

Definição da Rede Social: é importante definir qual rede social, entre as disponíveis na internet, será utilizada para a elaboração das narrativas digitais. Sua escolha precisa levar em consideração os recursos e funcionalidades que contribuirão com o desenvolvimento da narrativa digital. Os autores se basearam nos elementos das redes sociais Facebook e Twitter, uma vez que as mesmas possuem diferentes recursos midiáticos, entre outras funcionalidades.

Elaboração do Roteiro: nesta etapa do processo é preciso articular as informações coletadas de maneira lógica, por meio da interação dos personagens, e de forma que os subtemas/conteúdos específicos apareçam de forma lúdica. Deve-se estruturar a ordem em que os personagens irão aparecer no foco narrativo, quais mensagens serão expressas, os materiais utilizados em cada momento (por exemplo: vídeo, escrita, emoticon, fotografia), entre outros aspectos. Ressalta-se que nessa etapa, a criatividade do professor é relevante. Para a elaboração do roteiro, os autores utilizaram um processador de texto, sendo definidas as sequências de falas dos personagens, bem como imagens proporcionando um texto mais lúdico e motivador.

Validação do Conteúdo com Especialista: é necessário que o roteiro elaborado seja encaminhado para professores e pesquisadores da área no qual a narrativa digital está sendo proposta, tendo como objetivo obter sugestões sobre a percepção dos mesmos em relação ao vínculo entre os objetivos educacionais e o roteiro em si. Como forma de validação inicial, o roteiro (no formato textual) foi submetido à análise de 5 (cinco) docentes da área de eletrônica básica que atuam no ensino médio. Os mesmos apontaram sugestões e críticas, além de sugerirem expressões e falas que poderiam ser inseridas/modificadas no roteiro das narrativas digitais.

Desenvolvimento do Roteiro na Rede Social: nesta etapa deve ser realizada a criação dos perfis dos personagens; e o roteiro textual dever ser transcrito fazendo o uso das diferentes funcionalidades proporcionadas pela rede social. Assim, os autores realizaram a criação de diferentes perfis dos personagens relacionados com o contexto dos componentes elétricos/eletrônicos, como por exemplo: corrente elétrica; LED; diodo; indutor; professor; aluno; motor; entre outros. Para sua elaboração, foram inseridos nome, fotografia e a descrição de cada um deles. Posteriormente, o roteiro textual foi transcrito utilizando um template editável das redes sociais, evitando assim, a criação de perfis falsos (fakes) no Facebook e Twitter.

Disponibilização das Narrativas Digitais: nesta atividade, a disponibilização do conteúdo pode ocorrer de diferentes maneiras, como, por exemplo, de forma online, por meio da montagem de apresentações em Power Point, pela elaboração de uma apostila V. $18 \mathrm{~N}^{\mathrm{o}} 1$, julho, 2020 RENOTE DOI: 
contendo printscreen's, entre outras possibilidades. Ao final, os autores sintetizaram as narrativas digitais em um único documento textual e, de forma complementar, adicionaram comentários e orientações aos alunos e docentes sobre os elementos educacionais, conceitos e curiosidades presentes nas narrativas digitais.

\subsection{Descrição e Imagens das Narrativas Digitais}

As narrativas elaboradas no presente trabalho foram divididas em duas categorias, narrativas que utilizam: (1) elementos do Facebook; e (2) elementos do Twitter. As narrativas com foco nos elementos da rede social:

- facebook reproduzem diálogos/conversas entre personagens proporcionando uma história "lúdica" exemplificando uma situação-problema dos alunos em relação as temáticas dos componentes elétricos/eletrônicos.

- twitter apresentam o histórico dos componentes elétricos/eletrônicos, destacando a sua evolução, teorias, funcionamento, tendo o referido componente como personagem em primeira pessoa da narrativa.

A seguir é apresentado um exemplo de alguns trechos das narrativas digitais elaboradas com foco no elemento resistor. Ressalta-se que o conteúdo completo das narrativas digitais desenvolvidas no presente trabalho pode ser acessado pelo link: https://bit.ly/30nfd1.

Na Figura 3 é apresentado um trecho de uma narrativa digital utilizando elementos do Facebook. Nessa narrativa é representado um diálogo entre dois personagens sobre o componente elétrico "resistor" na qual é retratada uma situação comum em que a resistência de um chuveiro elétrico se queima. Neste contexto, temos uma explicação "lúdica" por meio do personagem resistor na qual ele relata o motivo que levou a queima do componente, juntamente com duas explicações a direita complementares ao fato ocorrido.

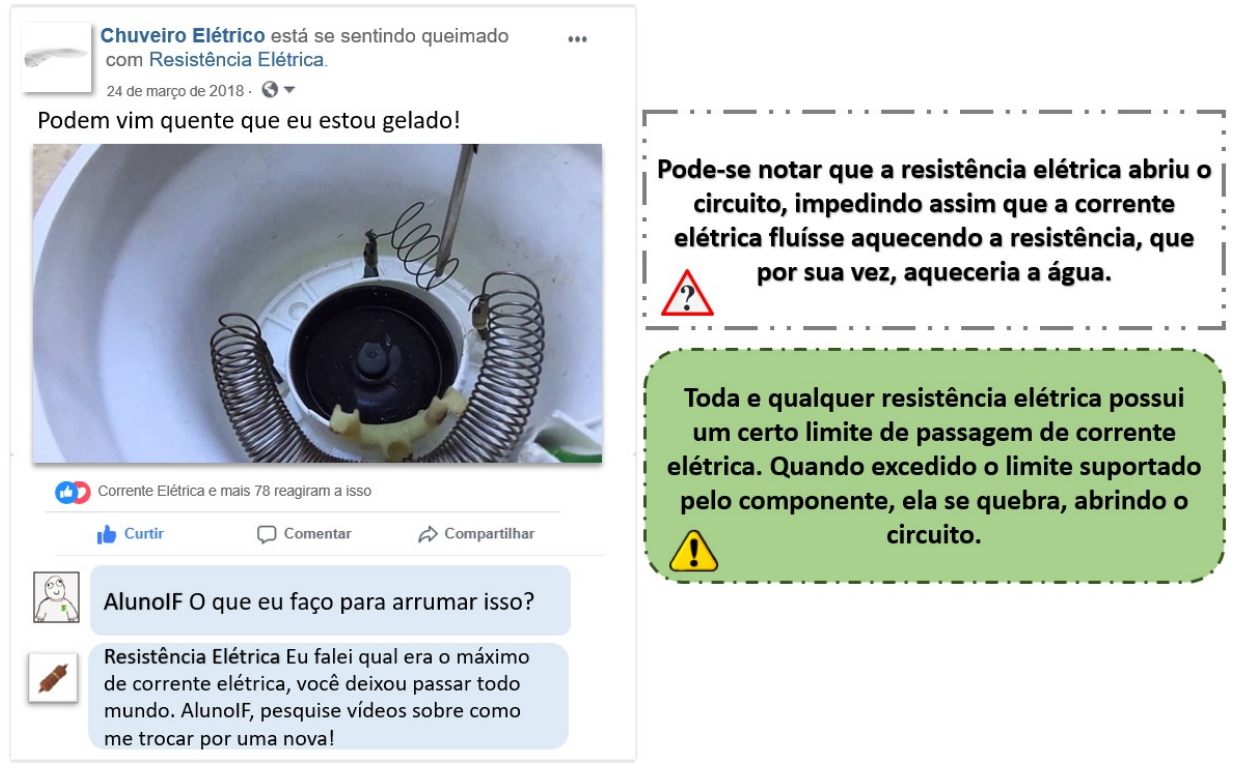

Figura 3 - Trecho de uma narrativa digital construída com elementos do Facebook.

A Figura 4 representa uma narrativa digital utilizando elementos do Twitter, que por sua vez irá trabalhar a história da evolução dos componentes de uma forma lúdica. Neste exemplo, o resistor é o personagem principal (em primeira pessoa) que está publicando fatos sobre o descobrimento da corrente elétrica, referenciando o cientista responsável pela descoberta como sendo o seu pai/criador. Também é apresentado um V. $18 \mathrm{~N}^{\mathrm{o}} 1$, julho, 2020 RENOTE DOI: 
elemento/quadro complementar a direita demonstrando a relação entre Tensão, Resistência e Corrente Elétrica - a formulação da "Primeira Lei de Ohm".
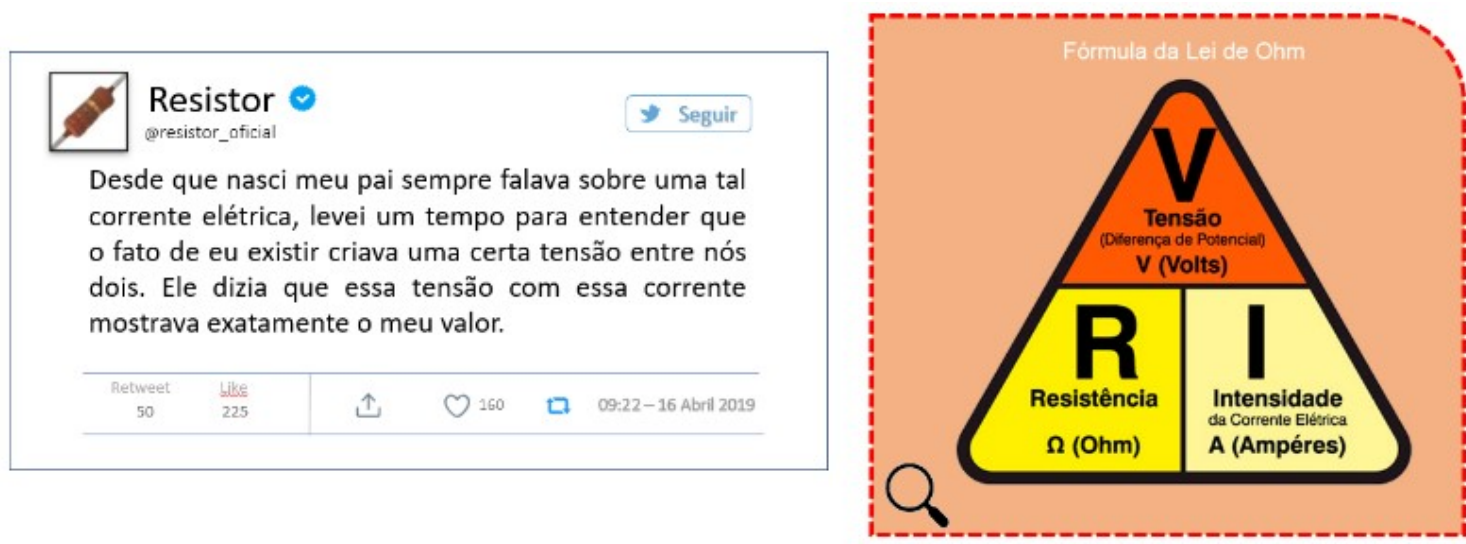

Figura 4 - Trecho de uma narrativa digital construída com elementos do Twitter.

Para cada narrativa digital também foram criados e inseridos elementos complementares à direita de cada narrativa digital (Exemplos nas Figuras 3 e 4), com o objetivo de proporcionar uma maior explicação por meio de comentários e curiosidades. Esses elementos (Figura 5), "caixas de texto e imagens", apresentam informações contendo termos técnicos, curiosidades adicionais, e explicações dos contextos que possam ser subentendidos nos trechos das narrativas.

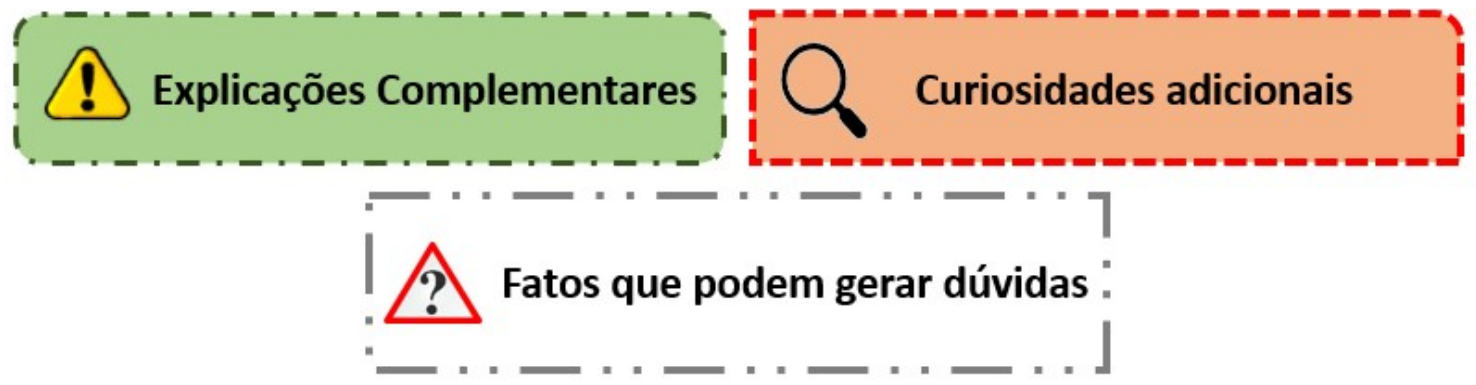

Figura 5 - Elementos complementares das narrativas digitais.

\section{Avaliação das Narrativas Digitais}

Esta seção apresenta uma avaliação prática das narrativas digitais desenvolvidas no presente trabalho. Para essa avaliação, foram utilizados alunos do curso do ensino médio integrado de automação industrial; e professores da área de Automação. O retorno/comentários dos participantes é importante para fornecer e identificar melhorias que podem ser incorporadas nas próximas versões das narrativas, verificando aspetos educacionais positivos e negativos.

Um total de 40 alunos (turmas do primeiro e segundo ano) participaram de uma aula no qual as narrativas digitais foram utilizadas como forma de recurso didático. A aula (duração de 30 minutos), aplicada pelos autores do trabalho, apresentou conceitos, aplicações e exemplificações dos componentes elétricos/eletrônicos presentes nas narrativas digitais. As narrativas foram apresentadas por meio de slides no projetor.

Ressalta-se que para cada turma, um conjunto diferente de narrativas foi apresentado relacionado com o conteúdo de ensino do ano escolar dos alunos. Exemplo, para a turma do primeiro ano foram apresentadas narrativas com foco nos componentes elétricos; no segundo ano vinculou-se aspectos dos componentes eletrônicos. 
É importante destacar que as narrativas digitais deste trabalho foram propostas como forma de complementação do ensino, assim, os alunos participantes em algum momento do ano letivo já tiveram contato com os respectivos conteúdos educacionais presentes nas narrativas.

Ao final da aplicação, um questionário online foi aplicado, sendo composto por critérios: Conteúdo Educacional; Elementos das Redes Sociais (Facebook/Twitter); Ludicidade; Acesso/Disponibilização; e Informações Complementares. Para cada critério foram incorporadas questões de múltipla escolha para facilitar o seu preenchimento. $\mathrm{O}$ questionário também possui ao seu final uma questão dissertativa permitindo aos participantes opinarem e destacarem aspectos positivos e negativos em relação as narrativas digitais e a aplicação prática realizada. A Tabela 1 apresenta os resultados obtidos da avaliação dos alunos juntamente com o número de itens e critérios avaliados.

Tabela 1 - Resultado do questionário com alunos.

\begin{tabular}{|c|c|c|c|c|}
\hline Critério & $\begin{array}{c}\text { Muito } \\
\text { satisfatório }\end{array}$ & Satisfatório & Regular & Insatisfatório \\
\hline Conteúdo Educacional (3 itens) & $91 \%$ & $9 \%$ & $0 \%$ & $0 \%$ \\
\hline $\begin{array}{c}\text { Elementos das Redes Sociais } \\
\text { (Facebook/Twitter) (3 itens) }\end{array}$ & $85 \%$ & $15 \%$ & $0 \%$ & $0 \%$ \\
\hline Ludicidade (2 itens) & $80 \%$ & $20 \%$ & $0 \%$ & $0 \%$ \\
\hline Acesso/Disponibilização (2 itens) & $65 \%$ & $30 \%$ & $5 \%$ & $0 \%$ \\
\hline Informações Complementares (2 itens) & $71 \%$ & $29 \%$ & $0 \%$ & $0 \%$ \\
\hline
\end{tabular}

Além da participação dos alunos, também houve a contribuições de professores especialistas. O questionário online foi aplicado aos professores em um momento distinto, possuindo questões diferenciadas, porém com foco nos mesmos critérios avaliados pelos alunos. A diferença no questionário dos professores foi a inclusão de questões referentes a avaliação do critério "Estrutura e Organização" das narrativas digitais. Este procedimento foi realizado com a participação de 5 (cinco) professores da área de automação, possuindo conhecimentos teóricos/práticos em relação aos componentes elétricos/eletrônicos. A Tabela 2 sintetiza os resultados obtidos por essa avaliação.

Tabela 2 - Resultado do questionário com professores da área.

\begin{tabular}{|c|c|c|c|c|}
\hline Critério & $\begin{array}{c}\text { Muito } \\
\text { satisfatório }\end{array}$ & Satisfatório & Regular & Insatisfatório \\
\hline Estrutura e Organização (3 itens) & $92 \%$ & $8 \%$ & $0 \%$ & $0 \%$ \\
\hline Conteúdo Educacional (4 itens) & $89 \%$ & $11 \%$ & $0 \%$ & $0 \%$ \\
\hline $\begin{array}{c}\text { Elementos das Redes Sociais } \\
\text { (Facebook/Twitter) (2 itens) }\end{array}$ & $91 \%$ & $9 \%$ & $0 \%$ & $0 \%$ \\
\hline Ludicidade (3 itens) & $92 \%$ & $8 \%$ & $0 \%$ & $0 \%$ \\
\hline Acesso/Disponibilização (2 itens) & $70 \%$ & $27 \%$ & $3 \%$ & $0 \%$ \\
\hline Informações Complementares (1 item) & $82 \%$ & $18 \%$ & $0 \%$ & $0 \%$ \\
\hline
\end{tabular}

Ao final, é possível concluir que as narrativas digitais utilizando elementos das redes sociais com foco na complementação do ensino de componentes 
elétricos/eletrônicos apresentaram uma boa aceitação tanto para alunos quanto para professores, possuindo níveis considerados aceitáveis frente a critérios educacionais.

As respostas das questões abertas foram sintetizadas, possibilitando uma visão crítica/complementar dos participantes; tanto alunos quanto professores tiveram pontos semelhantes em relação aos seguintes aspectos: (1) ausência de narrativas digitais complementares com foco em outros elementos da disciplina de eletrônica básica; (2) ausência de elementos mais "dinâmicos" nas narrativas, como por exemplo reprodução de vídeos, compartilhamento em tempo real, entre outros aspectos; (3) ausência de versões das narrativas em uma aplicação móvel, para sistemas operacionais móveis.

Ressalta-se que neste primeiro momento o conteúdo das narrativas digitais foi focado apenas em alguns componentes elétricos/eletrônicos, outros elementos/conteúdos da disciplina de eletrônica serão desenvolvidos e propostos pelos autores conforme as melhorias identificadas na avaliação dos participantes (alunos e professores). Por fim, as narrativas não utilizaram aspectos dinâmicos e disponibilização via aplicativo móvel pois o intuito foi o desenvolvimento de um material textual/paradidático estático, sendo possível a sua visualização em diferentes tipos de dispositivos móveis.

\section{Conclusão e Trabalhos Futuros}

Atualmente as TICs vêm ganhando espaço em diferentes áreas da sociedade, inclusive no contexto do ensino-aprendizagem de diferentes disciplinas.

Todavia, a área educacional da Eletrônica Básica pode ser considerada uma disciplina prática, mas ao mesmo tempo teórica e muito abstrata, pouco significativa, desestimulante e distante do universo de significação dos alunos, prejudicando o processo de ensino-aprendizagem. Verifica-se também uma carência e precariedade de recursos didáticos lúdicos e motivantes que possam ser utilizados como forma de complementação didática nas aulas de eletrônica.

Nesse cenário, tanto as redes sociais quanto as narrativas digitais estão sendo apresentadas em diferentes pesquisas como recursos tecnológicos capazes de gerar motivação e engajamento aos alunos, uma vez que favorecem a inserção do trabalho docente na realidade dos educandos, possibilitam a utilização de cenários e linguagens mais lúdicas, permitindo relações mais horizontais, entre outros benefícios capazes de contribuir com a promoção da aprendizagem. Sendo assim, buscou-se neste trabalho, desenvolver um conjunto de narrativas digitais utilizando elementos das redes sociais (Facebook e Twitter) e investigar a sua utilização na disciplina de Eletrônica Básica com foco nos componentes elétricos/eletrônicos, visando contribuir com a motivação dos alunos.

Como forma de avaliação das narrativas digitais, as mesmas foram aplicadas em duas turmas do ensino médio integrado do curso de automação industrial, e avaliadas também por professores especialistas da área. Ao final da aplicação, os participantes responderam um formulário online atribuindo as suas percepções positivas e negativas.

De modo geral, as narrativas digitais apresentaram uma boa avaliação em relação aos critérios: conteúdo educacional; ludicidade; estruturação didática; acesso; e informações complementares. Algumas limitações foram destacadas principalmente em relação a falta de elementos dinâmicos nas narrativas digitais; e a falta de um aplicativo móvel que pudesse reproduzir o acesso das narrativas digitais via dispositivos móveis.

Como trabalhos futuros os autores destacam: (1) a criação de um aplicativo móvel que possa reproduzir e disponibilizar as narrativas digitais, proporcionando maior dinamismo e flexibilidade aos utilizadores; e (2) o desenvolvimento e aplicação de outras narrativas digitais dentro do contexto da disciplina de Eletrônica Básica. Além V. $18 \mathrm{~N}^{\circ} 1$, julho, 2020 RENOTE DOI: 
disso, pretende-se realizar, em curto prazo, um novo experimento com graduandos do curso de Engenharia Elétrica e outros cursos correlatos, possibilitando coletar informações sobre a efetividade de utilização e aprendizagem das narrativas digitais em cursos superiores.

\section{Agradecimentos}

Agradecemos à FAPESP, CAPES e CNPq pelo auxílio financeiro concedido para a realização deste trabalho.

\section{Referências}

ALMEIDA, M. E. B.; VALENTE, J. A. Integração currículo e tecnologias e a produção de narrativas digitais. Currículo sem Fronteiras, v. 12, p. 57-82, 2012.

ALMEIDA, M. E. B.; VALENTE, J. A. Tecnologias digitais, linguagens e currículo: investigação, construção de conhecimento e produção de narrativas. In: Patrícia Lupion Torres. (Org.). Redes e conexões na produção do conhecimento. 1. ed. Curitiba: Kairós Editora, v. 1, p. 331-352, 2014.

ARAÚJO, V. D. L. O impacto das redes sociais virtuais no processo de ensino e aprendizagem. $3^{\circ}$ Simpósio Hipertexto e Tecnologias na Educação, 2010, Recife. Anais eletrônico do $3^{\circ}$ Simpósio Hipertexto, 2010.

AZEREDO, D. C.; REATEGUI, E. A construção de narrativas digitais como apoio ao processo de letramento. RENOTE - Revista Novas Tecnologias na Educação, 11(1). 2013.

CARITÁ, E. C.; PADOVAN, V. T.; SANCHES, L. M. P. Uso de redes sociais no processo ensino-aprendizagem: avaliação de suas características. $1^{\circ}$ Congresso Internacional ABED de Educação a Distância, Manaus, 2011.

FISCHER, D.; DUARTE FILHO, N. F. Proposta de um processo sistemático para construção de narrativas digitais utilizando redes sociais. Revista Tecnologias na Educação, v.28, p. 1-12, Dez, 2018.

JUNIOR, J. B. B.; LISBÔA, E. S.; COUTINHO, C. P. Narrativas digitais na formação inicial de professores: um estudo com alunos de licenciatura em Pedagogia. Revista Teias, v. 13, n. 27, p. 191-204, CURRÍCULOS: Problematização em práticas e políticas, 2012.

PRADO, A. L.; LAUDARES, E. M. de A.; VIEGAS, P. P. C.; GOULART, I. do C. V. Narrativas digitais: conceitos e contexto de letramento. Revista Ibero-Americana de Estudos em Educação, v. 12, n. esp. 2, p. 1156-1176, 2017.

SOUZA, A. A. N.; SCHNEIDER, H. N. Aprendizagem nas redes sociais: colaboração online na prática de ensino presencial. In: I Simpósio Internacional de Educação a Distância e I Encontro de Pesquisadores em Educação a Distância, 2012, São Carlos-SP, ANAIS do SIED: ENPED. São Carlos: UFSCar, 2012.

WERHMULLER, C. M.; SILVEIRA, I. F. Redes Sociais como ferramentas de apoio à Educação. In: II Seminário Hispano-Brasileiro de Avaliação das Atividades Relacionadas com Ciência, Tecnologia e Sociedade, v. 3. p. 594-605, 2012. 